\title{
Análise retrospectiva dos treinamentos de reanimação cardiorrespiratória
}

\author{
Éldina Rodrigues dos Santos*, Lauro César de Oliveira, M.Sc.**, Regimar Carla Machado, D.Sc.***
}

\begin{abstract}
*Enfermeira, Especialista em Enfermagem em Cuidados Críticos/Cardiologia da Universidade do Vale do Paraíba, Säo José dos Campos/SP, **Enfermeiro, Professor do Curso de Especialização de Enfermagem em Cuidados Críticos/Cardiologia da Universidade do Vale do Paraíba, São José dos Campos/SP, ***Enfermeira, Professora do Departamento de Enfermagem da Universidade Federal do Rio Grande do Norte, Natal/RN
\end{abstract}

\section{Resumo}

Objetivou-se investigar na literatura científica a caracterização dos estudos referentes ao enfermeiro na reanimação cardiopulmonar (RCP) quanto às manobras do suporte avançado de vida em cardiologia e averiguar a relevância do treinamento "in loco" de ressuscitação cardiopulmonar. A amostra foi composta de 27 artigos publicados no período de 2000 a 2012. Os artigos foram agrupados e os resultados divididos em cinco categorias temáticas: cursos da American Heart Association (AHA) em suporte básico de vida (SBV) e suporte avançado de vida em cardiologia (SAVC); fatores relacionados ao conhecimento da equipe de enfermagem em parada cardiorrespiratória (PCR); treinamento da equipe multidisciplinar em RCP; padrôes de ritmos encontrados na RCP. Observa-se a necessidade de um programa de capacitação para toda a equipe multidisciplinar para o atendimento da PCR, com a finalidade de padronizar, uniformizar as açôes de RCP, sobretudo, a melhora da sobrevida dos pacientes.

Palavras-chave: Enfermagem, parada cardiorrespiratória, ressuscitação cardiopulmonar, treinamento.

\section{Abstract}

\section{Retrospective analysis of training in cardiopulmonary resuscitation}

This study aimed at investigating in scientific literature studies that characterize the nurse performing cardiopulmonary resuscitation (CPR) related to advanced cardiac life support maneuvers and determining the relevance of training "in loco" cardiopulmonary resuscitation. The sample consisted of 27 articles which were published from 2000 to 2012 . The articles were grouped and the results divided into five thematic categories: courses from the American Heart Association (AHA) in basic life support (BLS) and advanced life support in cardiology (ALSC); factors related to knowledge of nursing team on management of cardiorespiratory arrest (CRA); multidisciplinary team training in CPR; rhythm patterns found in CPR. It was observed that a training program for all members of the multidisciplinary health team care on CRA is needed, in order to standardize and harmonize the actions of CPR, especially to improve survival in patients.

Key-words: Nursing, heart arrest, cardiopulmonary resuscitation, training. 59078-900 Natal RN, E-mail: regimarcarla@yahoo.com.br, eldinahfa@hotmail.com, lauro@univap.br 


\section{Resumen}

\section{Análisis retrospectivo de entrenamientos de resucitación cardiopulmonar}

Este estudio tuvo como objetivo investigar en la literatura científica la caracterización de estudios referentes al enfermero en la reanimación cardiopulmonar cuanto a las maniobras de soporte vital cardíaco avanzado y averiguar la relevancia del entrenamiento "in situ" de la reanimación cardiopulmonar. La muestra consistió en 27 artículos publicados en el período 2000-2012. Los artículos fueron agrupados y los resultados divididos en cinco categorías temáticas: cursos de la American Heart Association (AHA) en soporte vital básico (SVB) y soporte vital avanzado en cardiología (SVAC); los factores relacionados al conocimiento del personal de enfermería en un paro cardiorrespiratorio (PCR); el entrenamiento del equipo multidisciplinario en RCP; los patrones rítmicos que se encuentran en la RCP. Se observa la necesidad de un programa de capacitación para todo el equipo de atención multidisciplinario para el manejo del paciente en PCR, con el fin de estandarizar, uniformizar las acciones de RCP, sobretodo la mejora de la supervivencia en pacientes.

Palabras-clave: Enfermería, paro cardíaco, resucitación cardiopulmonar, entrenamiento.

\section{Introdução}

A parada cardiorrespiratória (PCR) pode ser definida como uma condição súbita e inesperada, na qual ocorre uma supressáo súbita da atividade ventricular útil e da respiração, gerando ausência de fluxo sanguíneo tecidual o que desencadeará danos celulares irreparáveis e irreversíveis em curto espaço de tempo [1].

No Brasil, segundo dados do DATASUS de 2012, houve uma média de $66,4 \%$ doenças do aparelho circulatório. Nos EUA a etiologia da doença coronariana é causa de 330.000 mortes anualmente, fora do hospital e no departamento de emergências (DE). No Brasil, corresponde a cerca de $160 \mathrm{mil}$ casos de mortes, uma média de 800 óbitos por dia, desse total 58 mil morrem de infarto do miocárdio $[2,3]$.

Nos Estados Unidos, por ano, cerca de 40.000 pessoas são vítimas da $\mathrm{PCR}$, na qual o retorno da circulação espontânea em hipofluxo cerebral acarreta a síndrome pós-PCR, caracterizada por comprometimento dos sistemas pulmonar, cardiovascular, renal, metabólico e neurológico. Com a finalidade de garantir um melhor prognóstico ao paciente, o enfermeiro deverá agir de forma sistêmica, sincrônica e harmoniosa [4].

Os profissionais de saúde devem reconhecer a PCR no menor intervalo de tempo possível, pois cada minuto perdido diminui em $10,0 \%$ a chance de sobrevida. No entanto, é essencial executar manobras de reanimação cardiopulmonar (RCP) e detectar as causas da PCR, agindo de forma uniforme e sistemática no atendimento às vítimas, baseada nas recomendaçóes do suporte avançado de vida em cardiologia (SAVC) [5].

Um estudo realizado, com alunos da graduação, em uma universidade privada no interior do estado de São Paulo, com objetivo de desenvolver um programa para capacitação do conhecimento teórico-prático, no atendimento a vítima de PCR, utilizando DEA, verificou que, após o programa de capacitação, houve melhoria significativa no conhecimento teórico-prático [6].

As manobras de RCP iniciam-se pelas compressóes torácicas, proporcionando o bombeamento do sangue, para fornecer oxigênio aos tecidos. As compressóes torácicas efetivas possibilitam a compressão ventricular, restabelecendo a circulação sanguínea espontânea e reperfundindo os órgãos vitais [6,7].

As manobras de RCP são compostas por um conjunto de procedimentos realizados de forma padronizada, durante a PCR, com o objetivo de restaurar a função de bomba do coração, para obter o retorno da circulação sanguínea espontânea, aumentando a sobrevida e a qualidade de vida da vítima [7].

Os guias de condutas que norteiam o atendimento a PCR foram desenvolvidos pela American Heart Association (AHA), através de um consenso da Aliança Internacional dos Comitês de Ressuscitação, ou seja, o Internacional Liaison Commitee on Resuscitation (ILCOR), para cursos de RCP e 
atendimento cardiovascular de emergência (ACE), desde 1970 [8].

As últimas diretrizes da AHA, publicadas em 2010, priorizam a circulação, a partir das compressóes torácicas, de no mínimo 100 por minuto, sobretudo, referente aos critérios de manobras básicas, a compressão torácica deve ser de duas polegadas (aproximadamente cinco centímetros) no adulto e de oito a 10 ventilaçóes por minuto [8].

Um estudo enfatizou que o treinamento de enfermeiras em suporte avançado de vida em cardiologia em atendimento prestado a pacientes vítimas de PCR foi avaliado, constatando que a chance de sobrevida foi quatro vezes maior para os pacientes que receberam atendimento de uma enfermeira treinada [9].

Outro estudo, realizado em hospital escola do interior do estado de São Paulo, para capacitação teórica dos enfermeiros sobre PCR/RCP, avaliou o conhecimento de dois grupos. Constatou-se que o grupo B foi superior ao grupo A, mas ambos melhoraram após a capacitação. Também, enfatizaram a importância da capacitação periódica [10].

O profissional enfermeiro deve ter conhecimento e estar preparado para identificar as urgências e emergências, visto que as possibilidades de sobrevivência após uma PCR variam de 2,0\% a $49,0 \%$, dependendo do ritmo cardíaco e do manejo da RCP [10].

Estudos mostram que a deficiência no atendimento da PCR está relacionada com a falta de descrição das tarefas da equipe de enfermagem e a deficiência em manuseio dos materiais e equipamentos, somados a falta de treinamentos específicos. Essas deficiências podem levar a um atendimento estressante e lento, o que piora a sobrevida do paciente $[6,10,11]$.

Existem evidências científicas que demonstram a eficiência da atuação na detecção da fibrilação ventricular (FV) e taquicardia ventricular (TV), pois estas arritmias estáo presentes em grande parte das causas de mortalidade, atingindo cerca de $5 \%$ dos pacientes internados. Assim, justifica manter uma equipe treinada e preparada, no ambiente hospitalar, para utilizar os cursos da AHA como base de treinamento e, o desfibrilador externo automático (DEA), para reduzir o intervalo de tempo para executar a desfibrilação $[11,12]$.

Um estudo que avaliou o conhecimento de 39 médicos emergencistas, com mais de cinco anos de graduaçáo, sobre o diagnóstico e tratamento da PCR, utilizando um questionário com 10 perguntas sobre PCR e RCP, detectou que o médico cardiologista com curso de SAVC apresentou um maior conhecimento em RCP, quando comparado com médicos de outras especialidades [13]. Ressaltando assim, a necessidade do treinamento periódico a todas as categorias e especialidades na área da saúde.

Um estudo descritivo, realizado em unidades não hospitalares de atendimento à urgência e emergência na regiáo metropolitana de Campinas, avaliou o conhecimento dos enfermeiros sobre PCR/ RCP e detectou um déficit no conhecimento em RCP. Além disso, constatou que quanto maior o intervalo de tempo entre um treinamento e outro, menor o conhecimento sobre as etapas de atendimento e tratamento da PCR [14].

$\mathrm{O}$ evento da PCR representa um grande desafio para a equipe de enfermagem, as diretrizes sobre SBV e SAVC são ferramentas essenciais para a segurança do atendimento às vítimas de PCR possibilitando o retorno da ventilação e da circulação espontânea, corroborando uma RCP de alta qualidade, a qual pode dobrar ou triplicar as taxas de sobrevida pós-PCR [15].

A equipe de enfermagem deverá assegurar a continuação do tratamento aos pacientes pós-PCR, como encaminhamento para a unidade de terapia intensiva (UTI) e monitoração dos parâmentros vitais. Contudo, do ponto de vista ético e legal os registros de procedimentos, evoluçáo e diagnóstico de enfermagem devem ser realizados no prontuário de forma objetiva, clara e completa. Portanto, o controle da pressáo arterial, diurese, glicemia, pressão intracraniana, temperatura, ventilação, sedação, eletrólitos e nutrição que complementam os cuidados ao paciente pós-PCR devem ser documentados [16,17].

Por meio da educação permanente, provavelmente, torna-se possível o treinamento in loco, no qual se desenvolve atividades práticas, eficazes e viáveis para a aplicação de treinamentos a equipe multiprofissional e, em especial pela equipe de enfermagem, a qual na maioria das vezes está presente no evento da PCR. Diante do exposto, este estudo objetivou investigar na literatura científica a caracterização dos estudos referentes ao enfermeiro na reanimação cardiopulmonar quanto às manobras do suporte avançado de vida em cardiologia e averiguar a relevância do treinamento in loco de ressuscitação cardiopulmonar. 


\section{Material e métodos}

Trata-se de um estudo descritivo-exploratório com abordagem quantitativa, de revisão integrativa da literatura. A referida pesquisa foi desenvolvida a partir das seguintes etapas: 1) Elaboração da pergunta norteadora; 2) Busca nas bases de dados: 3) Avaliação e análise dos dados.

Foram respeitados os direitos autorais das literaturas utilizadas neste estudo, conforme determinado na Lei no. 9610/1998 do Ministério da Educação e da Cultura (MEC).

- Etapa 1: A questáo norteadora do estudo consistiu em: quais são as principais condutas do enfermeiro no atendimento da PCR?

- Etapa 2: Foram pesquisados periódicos indexados nos bancos de dados do Sistema Latino Americano e do Caribe de Ciências da Saúde (Lilacs) e Scientific Electronic Library Online (Scielo) por intermédio da Biblioteca Virtual em Saúde (BVS) e Medline - Medical Literature and Retrieval System on line e Google Acadêmico. Realizou-se uma estratégia de busca utilizando os descritores e sinônimos consultados nos Descritores em Ciências da Saúde (DeCS) em três línguas: portuguesa, inglesa e espanhola.

Os descritores utilizados neste trabalho foram: Enfermagem, parada cardiorrespiratória, reanimação cardiorrespiratória, treinamento. A coleta de dados ocorreu no período de junho a julho de 2013.

O levantamento dos dados foi realizado a partir de uma busca nas bases de dados com credibilidade e com clareza dos resultados e de relevância dos artigos, com resultado em especial relação com a casualidade e a suas implicaçóes dos resultados na prática da enfermagem e no desenvolvimento teórico prático.

- Etapa 3: A amostra constituiu-se de 27 artigos sendo estabelecidos como critérios de inclusão artigos referentes a treinamento teórico/prático de PCR/RCP. Foram excluídos os artigos com mais de 12 anos de publicação e pesquisas que não foram publicadas na íntegra.

Foi utilizado um instrumento para coletar dados referentes ao título do artigo, objetivos, tipo de estudo/metodologia, identificação do estudo, resultados, conclusóes e observações relevantes.

\section{Resultados}

Os resultados estão demonstrados por meio de quadros e tabela, de acordo com os objetivos deste estudo. Foram selecionados 27 artigos completos, porém destes, cinco (18\%) foram excluídos, pois abordavam temas que não estavam relacionados ao objeto do estudo. Portanto, foram analisados 22 estudos. As temáticas apresentadas foram: parada cardiorrespiratória, reanimação cardiorrespiratória, treinamento, enfermagem e educação permanente.

$\mathrm{O}$ resultado referente aos anos de publicação para os descritores parada cardiorrespiratória, reanimação cardiopulmonar, treinamento e enfermagem, teve como objeto $22(100,0 \%)$ artigos completos. Observou-se uma maior produção no ano de 2008 e $2010(36,6 \%)$ e 2005, 2006, 2012 (40,90\%). Os anos de 2000, 2007 e 2009 (13,63\%) e 2011 (9,09\%), representando menor número de publicações. (Tabela I).

Tabela I - Percentual de publicações para os descritores utilizados. São José dos Campos, 2013 ( $n=22$ ).

\begin{tabular}{lc}
\hline \multicolumn{1}{c}{ Ano } & Percentual \\
\hline 2008,2010 & $36,60 \%$ \\
$2005,2006,2012$ & $40,90 \%$ \\
$2000,2007,2009$ & $13,63 \%$ \\
2011 & $9,09 \%$ \\
\hline
\end{tabular}

Conforme as categorizaçôes propostas neste estudo para os termos PCR, RCP, treinamentos e enfermagem os artigos foram selecionados pelo título, autores, ano, país, delineamento do estudo e desfecho.

\section{Discussão}

A análise dos dados quantitativos forneceu os resultados deste estudo, com um objetivo de fornecer informaçóes úteis aos profissionais de saúde para estarem preparados para atendimento à vítima de PCR, de forma sincrônica e eficaz, bem como melhorar a sobrevida dos pacientes.

Avaliar e rever as práticas de treinamento em RCP e sistematizá-las no sentido de efetivar os resultados. Os treinamentos devem ser sistematizados e alicerçados nas diretrizes e nas evidências científicas produzidas.

A equipe de enfermagem por ser mais presente à beira leito são na grande maioria os primeiros profissionais a detectar a PCR com o paciente em 
Quadro 1 - Caracterização das produções analisadas sobre os resultados dos treinamentos de reanimação cardiopulmonar às vítimas de parada cardiorrespiratória. São José dos Campos, 2013 ( $n=4)$.

\begin{tabular}{|l|l|l|l|}
\hline \multicolumn{1}{|c|}{ Título do artigo } & \multicolumn{1}{|c|}{ Autores/ País/ ano } & \multicolumn{1}{c|}{$\begin{array}{c}\text { Tipo de } \\
\text { pesquisa }\end{array}$} & \multicolumn{1}{c|}{ Desfecho } \\
\hline $\begin{array}{l}\text { In-hospital resuscitation: associa- } \\
\text { tion between ACLS training and } \\
\text { survival to discharge resuscitation } \\
{[9]}\end{array}$ & $\begin{array}{l}\text { Dane FC / USA / 2000 } \\
\text { Corte com- } \\
\text { parativa }\end{array}$ & $\begin{array}{l}\text { Os profissionais enfermeiros treinados em } \\
\text { protocolos de ACLS estão mais aptos a } \\
\text { identificar urgência de emergencia e ini- } \\
\text { ciar com os protocolos SAVC garantindo } \\
\text { uma melhor sobrevida. }\end{array}$ \\
\hline $\begin{array}{l}\text { Atendimento à parada cardior- } \\
\text { respiratória em unidade corona- } \\
\text { riana segundo o Protocolo Utstein }\end{array}$ & $\begin{array}{l}\text { Cavalcante TMC, Lopes / Brasil / 2006 [18] } \\
\text { RS }\end{array}$ & $\begin{array}{l}\text { Exploratório- } \\
\text {-descritiva }\end{array}$ & $\begin{array}{l}\text { O reconhecimento do tempo da parada, } \\
\text { as manobras de RCP, as medidas tomadas } \\
\text { após a PCR, utilizando o protocolo Utstein } \\
\text { para obter dados de prognóstico pós-RCP, } \\
\text { melhorando os registros dos prontuários } \\
\text { de cunho ético, legal e de pesquisa. }\end{array}$ \\
\hline $\begin{array}{l}\text { Determinants of the quality of ba- } \\
\text { sic life support by hospital nurses }\end{array}$ & $\begin{array}{l}\text { Verplance Paepe P, Calle } \\
\text { PA, De Regge M, Van } \\
\text { Maele G, Monsieurs } \\
\text { KGT / Bélgica / 2008 [5] }\end{array}$ & $\begin{array}{l}\text { Descritivo e } \\
\text { experimental }\end{array}$ & $\begin{array}{l}\text { A qualidade do Suporte Básico de Vida } \\
\text { resulta em melhor sobrevivência, e maior } \\
\text { segurança para os enfermeiros. }\end{array}$ \\
\hline $\begin{array}{l}\text { Educação Permanente em SBV e } \\
\text { SAVC: Impacto no Conhecimento } \\
\text { dos Profissionais de Enfermagem }\end{array}$ & $\begin{array}{l}\text { Lima SG, Macedo LA, } \\
\text { Vidal ML, Sá OMPB / } \\
\text { Brasil / 2009 [19] }\end{array}$ & $\begin{array}{l}\text { Descritivo } \\
\text { transversal }\end{array}$ & $\begin{array}{l}\text { O programa de treinamento permanente } \\
\text { em SBV e SAV resultou em um importante } \\
\text { aumento do conhecimento dos profissio- } \\
\text { nais de enfermagem. }\end{array}$ \\
\hline
\end{tabular}

Quadro 2 - Caracterização das produções analisadas sobre a conduta do Enfermeiro em reanimação cardiopulmonar às vítimas de parada cardiorrespiratória. São José dos Campos, 2013 ( $n=5)$.

\begin{tabular}{|c|c|c|c|}
\hline Título do artigo & Autores /País /ano & $\begin{array}{l}\text { Tipo de } \\
\text { pesquisa }\end{array}$ & Desfecho \\
\hline $\begin{array}{l}\text { Atendimento à parada cardior- } \\
\text { respiratória em unidade corona- } \\
\text { riana segundo o protocolo Utstein }\end{array}$ & $\begin{array}{l}\text { Cavalcante TMC, Lopes } \\
\text { RS / Brasil /2006 [18] }\end{array}$ & $\begin{array}{l}\text { Exploratório- } \\
\text {-descritiva }\end{array}$ & $\begin{array}{l}\text { O reconhecimento do tempo da parada, } \\
\text { as manobras de } R C P \text {, as medidas tomadas } \\
\text { após a } P C R \text {, utilizando o protocolo Utstein } \\
\text { para obter dados de prognóstico pós-RCP, } \\
\text { melhorando os registros dos prontuários } \\
\text { de cunho ético, legal e de pesquisa. }\end{array}$ \\
\hline $\begin{array}{l}\text { Determinants of the quality of ba- } \\
\text { sic life support by hospital nurses. } \\
\text { Resuscitation. }\end{array}$ & $\begin{array}{l}\text { Verplance Paepe P, Calle } \\
\text { PA, De Regge M, Van } \\
\text { Maele G, Monsieurs } \\
\text { KGT / Bélgica / 2008 [5] }\end{array}$ & $\begin{array}{l}\text { Descritivo e } \\
\text { experimental }\end{array}$ & $\begin{array}{l}\text { A qualidade Suporte Básico de Vida } \\
\text { resulta em melhor sobrevivência, e maior } \\
\text { segurança para os enfermeiros. }\end{array}$ \\
\hline $\begin{array}{l}\text { Capacitação do enfermeiro para } \\
\text { o atendimento da parada car- } \\
\text { diorrespiratória }\end{array}$ & $\begin{array}{l}\text { Bellan MC, Araújo IIM, } \\
\text { Araújo S / Brasil / } 2010 \\
{[10]}\end{array}$ & $\begin{array}{l}\text { Descritivo } \\
\text { experimental }\end{array}$ & $\begin{array}{l}\text { O desempenho dos sujeitos do grupo trei- } \\
\text { nado foi superior ao do grupo controle, } \\
\text { apresentaram conhecimentos superiores } \\
\text { sobre PCR/RCP. }\end{array}$ \\
\hline $\begin{array}{l}\text { Conhecimento teórico dos enfer- } \\
\text { meiros sobre parada e ressuscita- } \\
\text { ção cardiopulmonar em unidades } \\
\text { não hospitalares de atendimento } \\
\text { de urgência e emergência }\end{array}$ & $\begin{array}{l}\text { Almeida AO, Araujo } \\
\text { IEM, Darli MCB, Araujo } \\
\text { S Brasil / } 2011 \text { [14] }\end{array}$ & Descritivo & $\begin{array}{l}\text { Foi avaliado um conhecimento teórico } \\
\text { parcial em relação ao RCP de acordo com } \\
\text { a sequência das diretrizes da AHA. }\end{array}$ \\
\hline $\begin{array}{l}\text { Programa de capacitação em } \\
\text { ressuscitação cardiorrespiratória } \\
\text { com o uso do desfibrilador exter- } \\
\text { no automático }\end{array}$ & $\begin{array}{l}\text { Boaventura AP Miya- } \\
\text { dahira AMK / Brasil / } \\
2012 \text { [6] }\end{array}$ & $\begin{array}{l}\text { Exploratório } \\
\text { descritivo }\end{array}$ & $\begin{array}{l}\text { A avaliação do conhecimento teórico pra- } \\
\text { tica dos alunos de graduação da área da } \\
\text { saúde em RCP utilizando um DEA externo, } \\
\text { concluiu após o treinamento um desem- } \\
\text { penho eficaz. }\end{array}$ \\
\hline
\end{tabular}


ambiente hospitalar. Por esta razão torna-se imprescindível a atuação do enfermeiro presente na reanimação cardiopulmonar, sendo como profissional treinado e liderando sua equipe para maior eficácia na reanimação cardiopulmonar. Outro fator importante é que a qualidade do SBV resulta em melhor sobrevivência, e maior segurança para os enfermeiros [5].

A literatura descreve sobre curso de reciclagem para 296 enfermeiros em SBV, os quais realizaram a parte prática em um manequim conectado a um PC usando Skillreporting software System na Laerdal na Noruega. Notou-se que 43,0\% dos enfermeiros classificaram como bom e muito bom, e o sexo masculino se sobressaiu com uma melhor compressáo torácica, e uma maior confiança e o menor espaço de tempo entre os treinamentos refletiram em uma melhora das compressóes e maior confiança [5].

Observa-se que as diretrizes da AHA, a cada cinco anos, têm atualizado os protocolos de atendimento as vítimas de ACE e PCR intra e extra-hospitalar, através dos protocolos de RCP, com o objetivo de melhorar a sobrevida das vítimas de PCR e ACE. Vale ressaltar que nas diretrizes de 2010 houve uma implementação de mais um elo, no qual relata a importância de compressões torácicas de alta qualidade e o cuidado pós-PCR integrado $[8,20]$.

Para a familiarização das diretrizes de atendimento a PCR/RCP e ACE, foi necessário um determinado período de tempo, entre um treinamento e outro de três a seis meses, desde a sua criação em 1970. Essas diretrizes são revisadas e divulgadas de cinco em cinco anos pelos pesquisadores do atendimento de urgência e emergência. As publicaçóes sobre o atendimento às vítimas de PCR nos últimos anos demonstraram que a qualidade do atendimento à vítima de PCR está diretamente relacionada ao conhecimento teórico prático das reanimaçóes cardiorrespiratórias desempenhadas por um dos profissionais de saúde $[10,14]$.

Estudo de coorte comparativo, realizado em um hospital terciário da Georgia, com 120 enfermeiras, com e sem treinamento em ACLS, em unidades de UTI e unidade médico-cirúrgica, avaliou o atendimento prestado por enfermeiras com treinamento de SAVC e sem treinamento e foi constatado que dos pacientes vítimas de PCR que receberam atendimento de enfermeiras treinadas foi quase quatro vezes maior a chance de sobrevida [9].
Assim, é de vital importância que o profissional enfermeiro detenha o conhecimento para detectar e iniciar as manobras de SBV, favorecendo uma melhor sobrevida destes pacientes. Estudo demonstrou que $50 \%$ dos enfermeiros de ambos os grupos foram acertivos nas condutas, isso demostra que os enfermeiros estáo buscando espontaneamente conhecimento para melhor atendimento a vítimas em PCR. O programa de capacitação deve ser aplicado regularmente, com uma periodicidade trimestral ou semestral, pois, pode ser observado, que ocorre uma diminuição do conhecimento com o passar do tempo [10].

O profissional enfermeiro deve ter conhecimento e estar preparado para identificar as urgências e emergências, visto que as possibilidades de sobrevivência após uma PCR variam de $2 \%$ a $49 \%$, dependendo do ritmo cardíaco e do manejo da RCP. A AHA recomenda métodos de treinamentos permanentes para capacitar a equipe em SBV e SAV. Estes modelos de treinamentos estão entre os mais importantes capacitadores da equipe multiprofissional, pois tem elevado o conhecimento teórico-prático e se mostrado eficaz na RCP $[10,19]$.

Estudos mostram que a deficiência no atendimento da PCR está relacionada com a falta de descrição das tarefas da equipe de enfermagem e a deficiência em manuseio dos materiais e equipamentos somados a falta de treinamentos específicos. Essas deficiências podem levar a um atendimento estressante e lento, o que piora a sobrevida do paciente $[6,11,19]$.

Atendimento da vítima em PCR é um atendimento de urgência, pois é uma intercorrência inesperada e de maior gravidade, devido às sérias consequências que acarretam a vida do paciente. Todavia, observa-se a necessidade de um programa de capacitação para toda a equipe multidisciplinar para o atendimento da PCR, com a finalidade de padronizar, uniformizar as açóes de RCP, sobretudo, a melhora da sobrevida dos pacientes [12,14].

Estudos de casos reais de RCP mostraram que $50 \%$ das compressóes torácicas eram muito superficiais. Esses estudos também demonstraram que as compressóes torácicas eram interrompidas frequentemente durante a RCP [15,19]. Nas novas recomendaçóes os profissionais devem aplicar compressôes torácicas rápidas e profundas sem interrupçóes [8].

Estudo que diz respeito a enfermeiros, auxiliares e técnicos de enfermagem em SBV e SAV, atra- 
vés de um programa de treinamento permanente, realizado com 213 profissionais, dos quais 76 eram enfermeiros, 38 auxiliares e 99 técnicos, constatou que as médias estatísticas pré-treinamento foram diferentes entre enfermeiros $(4,69)$, auxiliares $(3,25)$, e técnicos $(3,96)$ e o conhecimento pré-treinamento foi dividido em partes diretamente proporcionais ao tempo de formação da graduação ou do curso técnico, resultando, após o treinamento, um aumento na porcentagem geral para 7,26 , sem diferenças estatísticas significantes [19].

Outros fatores que podem interferir são as variáveis referentes ao aluno, ao instrutor e ao próprio curso, como foi demonstrado em um estudo que avaliou o desempenho em relação a essas variáveis e concluiu que o profissional incentivado apresentou melhor aproveitamento, entretanto a questão financeira e a obrigatoriedade pode ser um fator que diminua o interesse [21].

Um estudo descritivo, realizado em unidades não hospitalares de atendimento à urgência e emergência na região metropolitana de Campinas, avaliou o conhecimento dos enfermeiros sobre PCR/RCP e detectou um déficit no conhecimento em RCP. Também constatou que quanto maior o intervalo de tempo entre um treinamento e outro, menor o conhecimento sobre as etapas de atendimento e tratamento da PCR [14].

Em uma unidade coronariana de um hospital universitário da cidade de São Paulo, utilizaram um guia de registros único e sistematizado para RCP, com o objetivo de melhorar os registros em prontuário das PCR/RCP, visto que em $90 \%$ dos prontuários os registros estavam incompletos [18]. O prontuário é um documento, legal e utilizado para pesquisas [16].

O êxito nas RCP depende da detecção precoce da PCR e o início imediato das compressóes torácicas de forma eficaz e rápida, para o retorno da circulação espontânea, o trabalho harmônico e o sincronismo da equipe [10].

Salienta-se a importância do reconhecimento da PCR, uma vez que o profissional de enfermagem constantemente detecta este evento e ao detectar a PCR, deverá solicitar ajuda e iniciar as manobras básicas de RCP, assim como todo atendimento avançado da PCR, desde que devidamente treinado [8].

Em relação à dinâmica no atendimento em PCR, o treinamento deverá ser permanente com cronogramas de treinamento a cada seis meses, no horário de trabalho, sem gerar perda da assistência e redução quanto ao número destes profissionais durante o plantáo. Outro ponto importante na $\mathrm{PCR} / \mathrm{RCP}$ são os registros de enfermagem para a realização das anotaçôes de forma sistemática e garantindo um registro para fins éticos, legais e também de pesquisa [11].

Após o atendimento à vítima da PCR e manobras de RCP, a equipe multidisciplinar deverá dar continuidade à assistência focando nos cuidados pós-PCR. A literatura apresenta a hipotermia como um dos avanços no tratamento pós-PCR, este tratamento vem sendo usado há mais de 50 anos em cirurgias cardíacas e, mais recentemente, em cirurgias neurológicas. Nos últimos dez anos teve grande impulso e tornou-se a terapêutica bem estabelecida no tratamento pós- PCR [7].

O desenvolvimento dos métodos terapêuticos de hipotermia nos pacientes que são reanimados tem uma porcentagem elevada acima de $65 \%$. Permanecer com déficit neurológico, resultado da ausência de circulação espontânea ou durante a reperfusão a hipotermia se apresenta como uma estratégia para diminuição das sequelas neurológicas. Para este paciente é necessário cuidados específicos nas 48 horas após a PCR, e há necessidade de um conhecimento da equipe para um melhor prognóstico $[4,8]$.

O diagnóstico da PCR deveria ser de 100,0\% assertiva para os enfermeiros, porém apenas $38,4 \%$ responderam corretamente e $61,6 \%$ parcialmente corretas. A avaliação da ausência do nível de consciência foi o menos assertivo, e foi avaliado em $67,1 \%$ com respostas parcialmente corretas à sequência da RCP, e na sequência do SBV o chamar ajuda, o carro de emergência com desfibrilador, ficou entre as respostas de menor acerto. Com relaçáo à avaliação do ritmo cardíaca FV/TVSP, apenas 12,3\% foram assertivos, $49,3 \%$ parcialmente e $38,4 \%$ não responderam corretamente [14].

$\mathrm{O}$ treinamento em RCP não deve ser entendido como mais um treinamento no atendimento assistencial, mas como um importante treinamento de alta relevância para salvar vidas. $O$ treinamento é transversal na medida em que interfere no resultado, que reflete diretamente na qualidade da RCP, o que é fator determinante para melhor sobrevida e menores índices de sequelas neurológicas [22,23].

O treinamento in loco apresenta características e estratégias de ensino teórico-prático, utilizando conteúdo do SAVC e recursos como data-show, um simulador/manequim tórax de RCP, máscara 
de ressuscitação e carro de emergência, para atualizaçáo no assunto e desenvolvimento de habilidades nas manobras de RCP, por meio de simulações de situaçôes próxima das reais.

\section{Conclusão}

A PCR no ambiente hospitalar é um evento frequente. Educação permanente em enfermagem voltada para atendimento PCR faz parte de um processo contínuo de ensino, aprimoramento, treinamento e atualizaçóes necessárias ao enfermeiro e toda a equipe de enfermagem. $\mathrm{O}$ treinamento em reanimação cardiopulmonar tem a finalidade de assegurar a competência técnica da equipe em relaçáo à prática diária de enfermagem, contribuindo para que o enfermeiro detenha mais conhecimento e, desta forma, empregar o treinamento em reanimação cardiopulmonar como práticas compatíveis.

\section{Referências}

1. Guimarães HP. Registro brasileiro de ressuscitação cardiopulmonar intra- hospitalar: fatores prognósticos de sobrevivência pós-ressuscitação [tese]. São Paulo: Instituto Dante Pazzanese de Cardiologia, Universidade de São Paulo; 2011.

2. Brasil, Ministério da Saúde. Datasus. Mortalidade dados preliminares. Brasília: MS; 2010.

3. Boehringer Ingelheim do Brasil R. Dados do Samu 2004. Doenças cardiovasculares. [citado 2013 Out 25]. Disponível em URL: http:// www.boehringer-ingelheim.com.br

4. Ravetti CG, Silva TO, Moura AD, Carvalho FB. Estudo de paciente reanimado pós-parada cardiorrespiratória intra e extra-hospitalar submetido à hipotermia terapêutica. Rev Bras Ter Intensiva 2009;21(4):369-75.

5. Verplancke T, De Paepe P, Calle PA, De Regge M, Van Maele G, Monsieurs KG. Determinants of the quality of basic life support by hospital nurses. Resuscitation 2008;77(1):75-80.

6. Boaventura AP, Miyadahira AMK. Programa de capacitaçáo em ressuscitação cardiorrespiratória com uso do desfibrilador externo automático Rev Gaúcha Enferm 2012;33(1):191-4.

7. Feitosa GSF, Sena JP, Guimarães HP, Lopes RD. Hipotermia terapêutica pós-reanimação cardiorrespiratória: evidências e aspectos práticos. Rev Bras Ter Intensiva 2009; 21(1):65-71.

8. American Heart Association. Diretrizes da AHA 2010 para RCP e ACE. Destaques das Diretrizes da American Heart Association para RCP e ACE 2010 [online]. 2010 [citado 2012 Jan 15]. Disponível em URL: http://www.slideshare.net/anestesiasegura/2010-aha-diretrizes-rcp

9. Dane FC, Russell-Lindgren KS, Parish DC, Durhan $\mathrm{MD}$, Brown TD. In-hospital resuscitation: association between ACLS training and survival to discharge. Resuscitation 2000; 47(1):83-7.

10. Bellan MC, Araújo IIM, Araújo S. Capacitação teórica do Enfermeiro para o atendimento da parada cardiorrespiratória. Rev Bras Enferm 2010;63(6):1019-27.

11. Fernandes AP, Vancini CR, Cohrs F, Moreira RSL. Qualidade das anotaçóes de enfermagem relacionadas à ressuscitação cardiopulmonar comparadas ao modelo Utstein. Acta Paul Enferm 2010; 23(6):757-63.

12. Moretti MA. Analise do atendimento intra-hospitalar de eventos simulados de fibrilação ventricular/taquicardia ventricular. Arq Bras Cardiol. 2005;84(6):449-51.

13. Barbosa FT, Barbosa LT, Silva AL, Silva KLG. Avaliação do diagnóstico e tratamento em parada cardiorrespiratória entre os médicos com mais de cinco anos de graduação. Rev Bras Ter Intensiva 2006;18(4):374-79.

14. Almeida AO, Araújo IEM, Dalri MCB, Araújo S. Conhecimento teórico dos enfermeiros sobre parada e ressuscitação cardiopulmonar, em unidades não hospitalares de atendimento de urgência e emergência. Rev Latinoam Enferm 2011;19(2):1-8.

15. Dalri MCB, Araújo IEM, Silveira RCCP, Canini SRMS, Cyrillo RMZ. Novas diretrizes da ressuscitaçáo cardiopulmonar. Rev Latinoam Enferm 2008;16(6):1060-2.

16. Assunção RC. Avaliação dos aspectos éticos e legais dos registros de enfermagem na parada cardiorrespiratória em hospital escola do Paraná [dissertaçáo]. Ribeirão Preto: Departamento de enfermagem geral e especializada da Escola de Enfermagem de Ribeirão Preto (SP): Universidade de São Paulo; 2005.

17. Pereira JCRG. Abordagem do paciente reanimado, pós-parada cardiorrespiratória. Rev Bras Ter Intensiva 2008;20(2):190-6.

18. Cavalcante TMC, Lopes RS.O atendimento à parada cardiorrespiratória em unidade coronariana segundo o Protocolo Utstein. Acta Paul Enferm 2006; 19(1):7-15.

19. Lima SG, Macedo LA, Vidal ML, Sá MPBO. Educação Permanente em SBV e SAVC: impacto no conhecimento dos profissionais de enfermagem. Arq Bras Cardiol 2009;93(6):630-6.

20. Berg RA, Hemphill R, Abella BS, Aufderheide TP, Cave DM, Hazinski MF et al. Part:5: adult basic life support: 2010 American Heart Association Guidelines for Cardiopulmonary Resuscitation and Emergency Cardiovascular Care. Circulation 2010;122(18 suppl3):S685-705.

21. Miyadahira AMK, Quilici AP, Martins CC, Araújo GLA, Pelliciotti JSS. Ressucitação cardiopulmonar com a utilizaçáo do desfibrilador externo semi-automático: avaliação do processo ensino - aprendizagem. Rev Esc Enferm USP 2008;42(3):532-8.

22. Miotto HC, Goulart EMA, Amaral CFS, Moreira MCV. Influência do subsídio financeiro e do local da realização do curso de suporte avançado de vida em cardiologia, no aprendizado da emergência cardiovascular. Arq Bras Cardiol 2008;90(3):191-4.

23. Ovalle CIS, Araújo S, Oliveira RARA, Dragosavac D. A importância do treinamento prévio no uso do desfibrilador externo automático por fisioterapeutas e enfermeiros. Rev Bras Ter Intensiva 2005;17(2):112-5. 